\title{
Salmonelas e coliformes fecais em águas de bebida para animais*
}

\section{Salmonellas and fecal coliforms in animal drinking water}

\author{
Luiz Carlos de Souza*, Sebastião Timo laria**, Gil Vianna Paim
}

\begin{abstract}
SOUZA, L.C. et al. Salmonelas e coliformes fecais em águas de bebida para animais. Rev.Saúde publ., S.Paulo, 26: 321-7, 1992. De um total de 402 propriedades rurais do Município de Botucatu, SP (Brasil) com atividades de exploração pecuária, foram sorteadas 60 (15\%) pelo processo de amostragem probabilística simples. Nestas 60 propriedades localizaram-se 113 bebedouros que eram os mais utilizados pelos animais para sua dessedentação. Foram colhidas amostras de água desses bebedouros visando a pesquisa de bactérias do gênero Salmonella, a determinação do Número Mais Provável (NMP) de bactérias coliformes fecais e a verificação do $\mathrm{pH}$ e da temperatura. Obteve-se isolamento positivo para salmonelas nas amostras de água de $15(13,27 \%)$ bebedouros correspondentes a 12 (20\%) das 60 propriedades visitadas, identificando-se os seguintes sorotipos: $S$. dublin, $S$. newport, $S$. madelia, S. IV 43:8, z57: -, S. saphra, S. glostrup, S. IV ochsenzool, S. I 9, 12:1: - e dois novos sorotipos $S$. IV 41:z52: - e S. IV 50:d:-. Das 113 amostras de água analisadas, 14 $(12,39 \%)$ apresentaram-se com NMP/100 mL de coliformes fecais acima de 4.000. Não foi constatada associação entre o isolamento positivo de salmonelas e NMP/100 mL de coliformes fecais acima de 4.000 . O isolamento de salmonelas e NMP/100 mL de coliformes fecais acima de 4.000 deu-se em temperaturas superiores a $18^{\circ} \mathrm{C}$ e em $\mathrm{pH}$ entre 6,0 e 7,0.
\end{abstract}

Descritores: Contaminação bacteriológica da água, análise. Salmonella, isolamento. Enterobacteriaceae, isolamento.

\section{Introdução}

Os animais mitigam a sede em qualquer local onde se acumula água. Sabe-se que microrganismos causadores de diferentes enfermidades animais podem ocorrer na água durante algum tempo e serem por ela transmitidos, como é o caso da salmonelose ${ }^{9}$. A capacidade das salmonelas sobreviverem fora dos hospedeiros, por períodos relativamente longos, proporciona outro dado importante ao se considerar a cadeia epidemiológica das salmoneloses ${ }^{6,16}$.

* Sintese da tese de Doutorado "Salmonelas e coliformes de origem fecal em amostras de águas usadas na dessedentação de animais do Município de Botucatu, São Paulo", apresentada em 1985, à Faculdade de Saúde Pública da Universidade de São Paulo. Apresentada no XX Congresso Brasileiro de Medicina Veterinária, realizado em Cuiabá (MT), 1986.

* Departamento de Higiene Veterinária e Saúde Pública Faculdade de Medicina Vetemária e Zootecnia - UNESP - Botucatu, SP - Brasil

*** Departamento de Microbiologia do Instituto de Ciências Biomédicas da Universidade de São Paulo - São Paulo, SP - Brasil

**** Departamento de Prática de Saúde Pública da Faculdade de Saúde Priblica da Universidade São Paulo - São Paulo, SP - Brasil

Separatas/Reprints: L.C. de Souza - Cx. Postal 513 - 18618000 - Rubião Júnior, SP - Brasil

Publicação financiada pela FAPESP. Processo Saude Coletiva 91/4994-0
Dependendo do tipo de exploração agropecuária, a dessedentação de animais feita em lagos, ribeirões, açudes, reservatórios ou mananciais que têm contato estreito com a própria pastagem pode constituir-se num risco de contaminação por salmonelas. Esses locais, freqüentemente, apresentam $o$ inconveniente de serem poluídos com excretas humanos e/ou animais.

Em trabalho de revisão, Wray ${ }^{19}$ refere a ocorrência de salmonelas em diversos corpos hídricos o que, conseqüentemente, acarreta problemas econômicos e de saúde em criações de animais. Um fato a ser assinalado na disseminação desta bactéria no ambiente é o despejo das águas servidas de matadouros em cursos de água, propiciando a infecção dos animais que se utilizam das águas rio abaixo.

Relativamente à presença de bactérias do gênero Salmonella em corpos hídricos e à sua relação com bactérias coliformes de origem fecal, podem ser destacados os trabalhos desenvolvidos por Geldreich ${ }^{12,13}$, nos EUA. Nestes constatou-se, em águas sem poluição e águas de estuário poluídas, um acentuado aumento na detecção de salmonelas quando os números mais provaveis (NMP) de coliformes fecais revelavam-se superiores a $200 / 100 \mathrm{~mL}$; quando os NMP atingiam números acima de $2.000 / 100$ 
$\mathrm{mL}$, obtinha-se $\mathrm{o}$ isolamento de salmonelas em, aproximadamente, $100 \%$ dos casos.

De acordo com o Decreto 8468 de 08 de setembro de $1976^{8}$, que classifica as águas interiores do Estado de São Paulo, podem ser utilizadas, na dessedentação de animais, as águas pertencentes até a classe 3. Para ser enquadrada nesta classe, $80 \%$ de pelo menos 5 amostras de água colhidas num período de até 5 semanas consecutivas, devem revelar-se com NMP de bactérias coliformes fecais de no máximo 4.000 por $100 \mathrm{~mL}$. Nesta pesquisa, apesar de ter sido analisada apenas uma amostra de cada bebedouro, as que se mostraram com NMP de coliformes fecais por $100 \mathrm{ml}$. superior a 4.000 , foram por nós consideradas como fora do padrão vigente ${ }^{8}$.

Devido as grandes implicações de ordem econômica e de saúde pública e animal que as bactérias do gênero Salmonella desempenham na atualidade, realizou-se esta pesquisa com as seguintes finalidades:

a) determinar o $\mathrm{NMP} / 100 \mathrm{~mL}$ de coliformes fecais e a presença de salmonelas em amostras de águas usadas na dessedentação de animais;

b) verificar nas amostras de águas analisadas a relação entre a presença de salmonelas e os NMP/100 mL de coliformes fecais;

c) relacionar a presença de salmonelas com os tipos de bebedouros utilizados;

d) verificar a relação existente entre a presença de salmonelas e a temperatura e $\mathrm{pH}$ das amostras de águas estudadas.

\section{Material e Método}

De um total de 402 propriedades rurais do Município de Botucatu, São Paulo, Brasil, que tinham entre suas atividades a exploração pecuária, foram sorteadas $60(15 \%)$ pelo processo de amostragem probabilística simples.

Localizou-se nessas 60 propriedades 113 bebedouros de variados tipos que eram os mais utilizados por diferentes espécies animais para sua dessedentação. De cada bebedouro era colhida uma amostra de água, na qual eram determinados a temperatura, o $\mathrm{pH}$, a presença de bactérias do gênero de Salmonella e o NMP/100mL de coliformes fecais.

- Determinação da temperatura:- era realizada com o auxílio de um termômetro comun com graduação até $100^{\circ} \mathrm{C}$. $\mathrm{O}$ bulbo do termômetro era mergulhado e a leitura da temperatura realizada após $10 \mathrm{~min}$.
- Determinaçāo do pH:- utilizou-se um potenciômetro, marca Coleman calibrado com soluções tampões, padrões, $\mathrm{pH} 4,0, \mathrm{pH} 7,0$ e $\mathrm{pH} 9,0$.

- Pesquisa de bactérias do gênero Salmonella:de cada bebedouro era colhida, com os cuidados de assepsia, uma amostra de água, de 5 litros, distribuída em dois Erlenmeyers esterilizados, de 3 litros e transportada ao laboratório em caixa isotérmica contendo cubos de gelo. $\mathrm{Na}$ pesquisa de salmonelas ${ }^{5}$, após homogeneização a água era vertida em um tanque de pressão em aço inoxidável (marca Millipore) com capacidade de 5 litros, esterilizado a $115^{\circ} \mathrm{C}$ por $20 \mathrm{~min}$, conectado a uma bomba de pressão e vácuo. Fechava-se o recipiente e procedia-se à filttração a uma pressão de 1 $\mathrm{kgf} / \mathrm{cm}^{2}$ através de uma membrana filtrante estéril, com diâmetro de $142 \mathrm{~mm}$ e porosidade de $0,45 \mu \mathrm{m}$, colocada no porta filtro (Millipore). Finalizada a operação de filtração, era em condições assépticas a membrana retirada e cortada em duas partes iguais. Uma delas era colocada em um Erlenmeyer contendo $250 \mathrm{~mL}$ de meio de Rappaport modificado por $\mathrm{Hoffer}^{5}$ e incubado em estufa bacteriológica a $37^{\circ} \mathrm{C}$ por $48 \mathrm{~h}$, e a outra em um Erlenmeyer contendo $200 \mathrm{~mL}$ de caldo seletito adicionado de novobiocina $^{5} \mathrm{e}$ incubado em banho-maria a $42,5^{\circ} \mathrm{C}$ por $48 \mathrm{~h}$. A partir destas culturas de enriquecimento procediam-se às passagens em placas de ágar MacConkey (Difco), ágar sulfito de bismuto (Difco), ágar verde brilhante (Difco) e ágar xilose-lisina-desoxicolato (Difco), seguida de incubação a $37^{\circ} \mathrm{C}$, por $24 \mathrm{~h}$. Após a incubação, eram isoladas colônias suspeitas de salmonelas, as quais eram incubadas em ágar tríplice açúcar-ferro, seguida de incubação a $37^{\circ} \mathrm{C}$, por $24 \mathrm{~h}$. Em seguida foram realizadas as identificações bioquímicas, seguido Edwards e Ewing ${ }^{10}$ e sorológica através das provas de soro aglutinação rápida, empregando soros polivalentes $\mathrm{O}$ e $\mathrm{H}$ produzidas no Instituto Adolfo Lutz de São Paulo. As cepas com características de Salmonella eram posteriormente sorotipadas nesse Instituto.

- Determinaçāo do NMP/100 ml de bactérias coliformes fecais:- Esta determinação foi realizada de acordo com os métodos padrão da American Public Health Association ${ }^{1}$, empregando-se a técnica dos tubos múltiplos. Assim na prova presuntiva foram inoculados volumes de $10 \mathrm{~mL}$ e $1 \mathrm{~mL}$ de água bruta, respectivamente, em 5 tubos de caldo lactosado (Difco) 
com tubo de Durham em seu interior. A seguir foram feitas diluições da amostra, de $10^{-1}$ a $10^{-4}$, sendo o diluente água fosfatada $\mathrm{pH} 7,2$, esterilizada, das quais foram também inoculados volumes de $1 \mathrm{~mL}$ cada, respectivamente, em 5 tubos de caldo lactosado, com tubo de Durham. Todos os tubos eram incubados a $35 \pm 2^{\circ} \mathrm{C}$. As leituras realizadas após 24 e $48 \pm 2$ horas. Em seguida, a partir dos tubos com produção de gás, procedia-se à prova de confirmação para coliformes fecais, através de semeadura em caldo EC (Difco), usando-se alça de níquel-cromo, com $3 \mathrm{~mm}$ de diâmetro.

Os tubos eram incubados em banho-maria a $44,5 \pm 0,5^{\circ} \mathrm{C}$, durante $24 \mathrm{~h}$. Consideravam-se como positivos para coliformes fecais, os tubos de caldo EC que revelavam produção de gás.

A partir das porçōes positivas e empregando-se a Tabela dos NMP, de Hoskins (CETESB $^{4}$ ), deterninava-se o NMP de coliformes fecais por $100 \mathrm{~mL}$ da amostra.

Os valores dos $\mathrm{NMP} / 100 \mathrm{~mL}$ obtidos com relação a coliformes fecais foram comparados com os exigidos pelo Decreto $\mathrm{n}^{2} 8468$ de 8.9.76 que classifica as águas interiores do Estado de São Paulo ${ }^{8}$, padrão este vigente quando da realização do presente estudo.

- Análise Estatística:- A análise dos resultados obtidos foi realizada calculando-se as estatísticas $\mathrm{X}^{2}$ para o teste de associação entre os fatores (para $\lambda=0,05$ ), nos casos recomendados por Fleiss ${ }^{11}$.

\section{Resultados e Discussão}

O controle da salmonelose é dificulatado devido a existência de animais portadores de salmonelas, eliminando-as constantemente com as fezes e poluindo desta forma o meio ambiente ${ }^{2,18}$. Assim sendo, os bebedouros podem constituir importantes fontes de infecção, considerando-se não só os hábitos dos animais

Tabela 1. Número Mais Provável (NMP) por $100 \mathrm{~mL}$ de coliformes fecais e isolamento de sorotipos de bactérias do gênero Salmonella em águas usadas na dessedentação de animais, segundo os tipos de bebedouros. Botucatu, SP, 1982.

\begin{tabular}{|c|c|c|c|c|c|c|c|}
\hline \multirow{3}{*}{$\begin{array}{l}\text { Bebedouros } \\
\text { Tipo } \\
\end{array}$} & \multirow[b]{3}{*}{$\mathrm{N}^{2}$} & \multirow[b]{3}{*}{$\%$} & \multirow{2}{*}{\multicolumn{2}{|c|}{$\begin{array}{l}\text { Coliformes Fecais } \\
\text { com NMP/100mL } \\
\text { acima de } 4.000\end{array}$}} & \multirow[b]{3}{*}{$\mathrm{N}^{2}$} & \multicolumn{2}{|c|}{ Amostras positivas para salmonelas } \\
\hline & & & & & & & \\
\hline & & & $\mathrm{N}^{2}$ & $\%$ & & $\%$ & Sorotipos \\
\hline $\begin{array}{l}\text { Caixa de cimento } \\
\text { e caixa de zinco } \\
\text { (Tipo 1) }\end{array}$ & 40 & 35,4 & 3 & 7,5 & 4 & 10,0 & $\begin{array}{c}\text { S.dublin (1), S.madelia (2) } \\
\text { S.glostrup (1) }\end{array}$ \\
\hline $\begin{array}{l}\text { Banheira } \theta \\
\text { tambor metálico } \\
\text { (Tipo 2) }\end{array}$ & 19 & 16,8 & 6 & 31,6 & 3 & 15,8 & S.dublin (2), S.IV 50:d:-(1) \\
\hline $\begin{array}{l}\text { Córrego e } \\
\text { riacho } \\
\text { (Tipo 3) }\end{array}$ & 26 & 23,0 & 0 & 0 & 2 & 7,7 & $\begin{array}{l}\text { S.I } 9,12(1)- \\
\text { S.IV } 43: 9,2,57(1)\end{array}$ \\
\hline $\begin{array}{l}\text { Calha e } \\
\text { bico de mamadeira } \\
\text { (Tipo 4) }\end{array}$ & 3 & 2,6 & 0 & 0 & 0 & 0 & 0 \\
\hline $\begin{array}{l}\text { Represamento } \\
\text { e açude } \\
\text { (Tipo 5) }\end{array}$ & 18 & 15,9 & 4 & 22,2 & 5 & 27,8 & $\begin{array}{l}\text { S.Newport (2), S.IV } 41: 2 \text { 52:-(1) } \\
\text { S.IV } 43: 9,2,57:-(1), \text { S.saphra (1) }\end{array}$ \\
\hline $\begin{array}{l}\text { Charco } \\
\text { (Tipo 6) }\end{array}$ & 7 & 6,2 & 1 & 14,3 & 1 & 14,3 & S.IV ochsenzool (1) \\
\hline Total & 113 & 100,0 & 14 & 12,4 & 15 & 13,3 & \\
\hline
\end{tabular}

Para coliformes fecais $X^{2}=12,659 p\left(0,02\right.$. Para salmonelas $X^{2}=4,566 p>0,30$ 
durante o ato de beber água, como também as características dos bebedouros que podem ser de diferentes tipos, contribuindo assim para o aumento da incidência de salmonelose.

Considerando a região de Botucatu, S.Paulo, Brasil, e analisando-se a Tabela 1, pode-se verificar que dos 113 bebedouros estudados, $51(45,1 \%)$ eram naturais, sendo 26 $(23,0 \%)$ representados por córregos e riachos (tipo 3), $18(15,9 \%)$ por represa:- mentos e açudes (tipo 5 ) e $7(6,2 \%)$ por charcos. Nestes tipos de bebedouros os animais quase sempre têm contato com a água, podendo inclusive defecar no local utilizado para sua dessedentação. Os demais tipos de bebedouros, sendo $40(35,4 \%)$ constituídos por caixas de cimento e zinco (tipo 1), $19(16,8 \%)$ por banheiras e tambor metálico (tipo 2) e $3(2,6 \%)$ por calhas e bicos de mamadeira (tipo 4), apesar de poderem contaminar-se com salmonelas e outros microrganismos, devem representar menor risco.

No Estado de São Paulo, Leitão ${ }^{15}$, analisando 116 amostras de águas fluviais das regiões de Campinas e de Vale do Paraíba, obteve um elevada positividade para salmonelas, ou seja, de 79,3\%. O autor atribui a origem dessas salmonelas à ocorrência de poluição fecal oriunda de animais domésticos e/ou selvagens existentes na região. Outros autores, analisando a presença de coliformes fecais encontraram níveis apreciáveis de poluição fecal (Christovão e col. ${ }^{3}$; Costa e col. ${ }^{7}$; Satake e col. ${ }^{17}$ ). Esses autores, embora não tenham pesquisado salmonelas, verificaram que as águas analisadas representavam risco quanto à trans-

Tabela 2. Isolamento de bactérias do gênero Salmonella em amostras de água de dessedentação animal. Botucatu, SP, 1982.

\begin{tabular}{lcc}
\hline $\begin{array}{c}\text { Isolamento } \\
\text { de }\end{array}$ & \multicolumn{2}{c}{ Amostras } \\
\cline { 2 - 3 } salmonelas & $\mathrm{N}^{2}$ & $\%$ \\
\hline Positivo & 15 & 13,3 \\
Negativo & 98 & 86,7 \\
\hline Total & 113 & 100,0 \\
\hline
\end{tabular}

Tabela 3. Coliformes fecais (NMP/100 mL)* em amostras de água de dessedentação animal. Botucatu, SP, 1982

\begin{tabular}{ccc}
\hline Coliformes fecais & \multicolumn{2}{c}{ Amostras } \\
\cline { 2 - 3 } NMP/100mL & $N^{2}$ & $\%$ \\
\hline 44.000 & 99 & 87,6 \\
$\geq 4.000$ & 14 & 12,4 \\
\hline Total & 113 & 100,0 \\
\hline NMP/100mL = Número Mais Provável em $100 \mathrm{~mL}$
\end{tabular}

da amostra. missão de agentes intestinais patogênicos.

Analisando-se a Tabela 2, constata-se que das 113 amostras de águas utilizadas pelos animais, $15(13,3 \%)$ revelaram-se positivas para salmonelas. Neste levantamento, que é o primeiro desta natureza realizado na região, estudada, apesar da positividade não ser elevada, revestese de significado epidemiológico, visto que um número variável de animais utilizavam tais águas para sua dessedentação, expondo-se ao risco de contraírem infecções, com ou sem sintomas, por diferentes sorotipos de Salmonella.

Pela Tabela 3, das 113 amostras analisadas, $14(12,4 \%)$ mostraram-se com NMP de coliformes fecais acima do limite, podendo representar risco eminente para a saúde dos animais.

$\mathrm{Na}$ Tabela 4, pode-se constatar que das 15 amostras positivas para salmonelas, apenas uma $(0,9 \%)$ revelou-se com $\mathrm{NMP} / 100 \mathrm{~mL}$ superior a $4.000 \mathrm{e}$, portanto, fora do padrão. Diante disto não se verificou associação entre o NMP $/ 100 \mathrm{~mL}$ superior a 4.000 e o isolamento positivo para salmonelas. Isto coincide com os resultados obtidos por alguns autores, como por exemplo, Leitão ${ }^{15}$. Entretanto, em região do País, Martins e col. ${ }^{16}$ examinando amostras de águas doces verificaram uma relação praticamente linear entre o isolamento de salmonelas e os níveis dos NMP de coliformes totais e fecais.

Pela Tabela 1 constata-se que a maior positividade para salmonelas obteve-se das amostras de água colhidas de bebedouros do tipo 5 constituído por represamentos e açudes $(27,8 \%)$. Das amostras colhidas em calhas e bicos de mamadeira (tipo 4) não se constatou a presença de salmonelas.

Relativamente ao isolamento de salmonelas e sua relação com a temperatura e o pH, nas Tabela 5 e 6 constata-se, aparentemente, positividade maior na faixa de $\mathrm{pH}$ entre $6,0 \mathrm{e}$ 7,0 , exclusive, e temperatura superior a $18^{\circ} \mathrm{C}$.

Das amostras de água de 15 bebedouros $(13,3 \%)$ localizados em 12 propriedades $(20,0 \%)$, foram isolados 8 sorotipos: S. dublin,

Tabela 4. Isolamento de bactérias do gênero Salmonella $\theta \mathrm{NMP} / 100 \mathrm{~mL}$ de coliforme fecais em amostras de água de dessedentaçāo animal. Botucatu, SP, 1982.

\begin{tabular}{|c|c|c|c|}
\hline \multirow{2}{*}{$\begin{array}{c}\text { Isolamento } \\
\text { de } \\
\text { Salmonelas }\end{array}$} & \multicolumn{2}{|c|}{$\begin{array}{l}\text { Coliformes fecais com } \\
\text { NMP/100mL acima de } 4.000\end{array}$} & \multirow{2}{*}{$\begin{array}{c}\text { Total de } \\
\text { amostras } \\
\text { examinadas }\end{array}$} \\
\hline & $\mathrm{N}^{2}$ & $\%$ & \\
\hline Positivo & 1 & 0,9 & 15 \\
\hline Negativo & 13 & 11,5 & 98 \\
\hline Total & 14 & 12,4 & 113 \\
\hline
\end{tabular}


Tabela 5. Isolamento de bactérias do gênero Salmonella e NMP/100 mL de coliformes fecais segundo a temperatura da água dos bebedouros usados para a dessedentação de animais. Botucatu, SP, 1982.

\begin{tabular}{|c|c|c|c|c|c|}
\hline \multirow{2}{*}{$\begin{array}{l}\text { Temperatura } \\
\text { da água dos } \\
\text { bebedouros }\end{array}$} & \multicolumn{2}{|c|}{$\begin{array}{l}\text { Amostras positivas } \\
\text { para Salmonelas }\end{array}$} & \multicolumn{2}{|c|}{$\begin{array}{l}\text { Coliformes fecais com } \\
\text { NMP/100 mL acima de } 4.000\end{array}$} & \multirow{2}{*}{$\begin{array}{c}\text { Amostras } \\
\text { Examinadas } \\
\mathrm{N}^{2}\end{array}$} \\
\hline & $\mathrm{N}^{2}$ & $\%$ & $\mathrm{~N}^{2}$ & $\%$ & \\
\hline $12 \vdash 14$ & 0 & 0 & 1 & 0,9 & 2 \\
\hline $14 \vdash 16$ & 3 & 2,6 & 2 & 1,8 & 21 \\
\hline $16 \vdash 18$ & 1 & 0,9 & 3 & 2,6 & 13 \\
\hline $18 \vdash 20$ & 6 & 5,3 & 0 & 0 & 35 \\
\hline $20 \vdash 22$ & 2 & 1,8 & 7 & 6,2 & 31 \\
\hline $22 上$ & 3 & 2,6 & 1 & 0.9 & 11 \\
\hline Total & 15 & 13,3 & 15 & 12,4 & 113 \\
\hline
\end{tabular}

Tabela 6. Isolamento de bactérias do gênero Salmonella $\theta$ NMP/100 mL de coliformes fecais segundo o pH da água dos bebedouros usados para a dessedentação de animais. Botucatu, SP, 1982.

\begin{tabular}{|c|c|c|c|c|c|}
\hline \multirow{2}{*}{$\begin{array}{c}\text { pH da água } \\
\text { dos } \\
\text { Bebedouros }\end{array}$} & \multicolumn{2}{|c|}{$\begin{array}{l}\text { Amostras positivas } \\
\text { para salmonelas }\end{array}$} & \multicolumn{2}{|c|}{$\begin{array}{l}\text { Coliformes fecais com } \\
\text { NMP/ } 100 \mathrm{~mL} \text { acima de } 4.000\end{array}$} & \multirow{2}{*}{$\begin{array}{c}\text { Amostras } \\
\text { Examinadas } \\
\mathrm{N}^{2}\end{array}$} \\
\hline & No & $\%$ & $\mathrm{~N}^{2}$ & $\%$ & \\
\hline $5,0 \vdash 6,0$ & 1 & 0,9 & 0 & 0 & 6 \\
\hline $6,0 \vdash 7,0$ & 10 & 8,8 & 12 & 10,6 & 65 \\
\hline $7,0 \vdash 8,0$ & 4 & 3,5 & 2 & 1,8 & 32 \\
\hline 8.01 & 0 & 0 & 0 & 0 & 10 \\
\hline Total & 15 & 13,3 & 14 & 12,4 & 113 \\
\hline
\end{tabular}

S. newport, S. madelia, S. IV 43:g, z57:-, S. saphra, S. glostrup, S. IV ochsenzool e $S$. I 9,12:i:-; foram isolados também cepas de dois sorotipos que não haviam sido ainda descritos. Essas cepas*, foram confirmadas como pertencentes aos sorotipos $S$. IV 41:z52:- e $S$. IV 50:d:-, catalogadas no Instituto Pasteur ${ }^{14}$. O sorotipo, aparentemente mais freqüente foi $S$. dublin com 20,0\% de isolamento (Tabela 7).

Analisando-se a Tabela 1, constata-se que

Tabela 7. Sorotipos de salmonelas isolados da água de bebedouros usados para a dessedentaçāo de animais, localizados em 12 propriedades. Botucatu, SP, 1982.

\begin{tabular}{lcc}
\hline Sorotipos & \multicolumn{2}{c}{ Bebedouros positivos } \\
\cline { 2 - 3 } isolados & $N^{2}$ & $\%$ \\
\hline S. dublin & 3 & 20,0 \\
S. IV 43:9,257:- & 2 & 13,3 \\
S. newport & 2 & 13,3 \\
S. madelia & 2 & 13,3 \\
S. IV 41:z52:- & 1 & 6,7 \\
S. glostrup & 1 & 6,7 \\
S. IV ochsenzool & 1 & 6,7 \\
S. IV 50:d:- & 1 & 6,7 \\
S. I 9,12:i:- & 1 & 6,7 \\
S. saphra & 1 & 6,7 \\
\hline Total & 15 & 100,0 \\
\hline
\end{tabular}

* Confirmação realizada pelo Prof. Le Minor, do Instituto Pasteur de Paris. os bebedouros, banheiras e tambor metálico (tipo 2), represamentos e açudes (tipo 5) e charco (tipo 6), foram os que se revelaram com águas altamente poluídas, pois, em $31,6 \%, 22,2 \%$ e $14,3 \%$, respectivamente, os $\mathrm{NMP} / 100 \mathrm{~mL}$ de coliformes fecais foram superiores a $4.000 \mathrm{e}$, portanto, não deveriam ser utilizados na dessedentação de animais, de acordo com o padrão vigente ${ }^{8}$, quando da realização do trabalho (coletas realizadas de $12 / 4 / 82$ a $10 / 5 / 83$ ).

Das amostras analisadas, e observando as Tabelas 5 e 6 , constata-se que as que se encontravam com NMP acima do limite estabelecido pela legislação, tinham temperatura compreendida entre $20^{\circ} \mathrm{C}$ e $22^{\circ} \mathrm{C}(6,2 \%)$ e o $\mathrm{pH}$ entre 6,0 e $7,0(10,6 \%)$.

Como, das 60 propriedades visitadas, em $12(20,0 \%)$ foram isoladas salmonelas das amostras de águas, nota-se a importância da qualidade sanitária das mesmas. Diante dos resultados obtidos na presente investigação destaca-se a importância quanto a educação sanitária dos profissionais que atendem as propriedades de criações animais.

Dada a defasagem de 10 anos dos dados da presente pesquisa, talvez não existam mais salmonelas nas águas examinadas, ou quem sabe os poços foram extintos, mas a importância epidemiológica do estudo continua sendo válida. 


\section{Conclusões}

Das 113 amostras analisadas, obteve-se o isolamento de salmonelas de $15(13,3 \%)$, mostrando que águas usadas na dessedentação podem representar risco aos animais em relação a salmonelose.

Ainda na conclusão deste trabalho inferese que:

- Estatisticamente não houve associação entre o isolamento de salmonelas e o NMP/100mL de coliformes fecais; isto significa que o encontro de números elevados de coliformes fecais nem sempre está relacionado à presença de salmonelas.

- A positividade para o isolamento de salmonelas foi maior quando a temperatura da água era superior a $18^{\circ} \mathrm{C}$ e o pH entre 6,0 e 7,0 .

- A maior percentagem de isolamentos positivos para salmonelas ocorreu nos bebedouros constituídos por represamentos e açudes (27,8\%).

- Foram isoladas cepas de 8 sorotipos de bactérias do gênero Salmonella, e mais dois não descritos na literatura mundial, os quais foram classificados como $S$. IV 41:z52:- e $S$. IV 50:d:-

- A maior percentagem de amostras de águas com coliformes fecais acima de $4.000 / 100 \mathrm{~mL}$ relacionou-se aos bebedouros dos tipos banheiras e tambor metálico $(31,6 \%)$.

- Em relação ao $\mathrm{NMP} / 100 \mathrm{~mL}$ de coliformes fecais acima de 4.000 , a maior percentagem ocorreu quando as temperaturas se revelaram entre $20^{\circ} \mathrm{C}$ e $22^{\circ} \mathrm{C}$ e o pH entre 6,0 e 7,0 .

\section{Agradecimentos}

Ao Instituto Adolfo Lutz, da Secretaria do Estado da Saúde de São Paulo, em especial à bióloga Kinue Trino (M. Se.) pela identificação final das amostras de Salmonella; ao Prof. Le Minor, do Instituto Pasteur de Paris pela sorotipificação final de algumas amostras de Salmonella; ao Prof. Dr. Paulo Roberto Curi, do Serviço de Estatística e Computação da Faculdade de Medicina Veterinária e Zootecnia UNESP - Campus de Botucatu, pelas análises estatísticas realizadas.

SOUZA, L.C. et al. [Salmonellas and fecal coliforms in animal drinking water]. Rev.Saúde públ., S.Paulo, 26: 321-7, 1992. Sixty small farms of Botucatu County, S.Paulo, Brazil, given over to 326 cattle breeding were studied. These farms account for $15 \%$ of the total of 402 farms that exist in the county. The sample was drawn by simple probabilistic technique. There were found to be one hundred and thirteen drinking places located on the farms. Samples of water were taken from these drinking places and examined for bacteria of the genus Salmonella, for the determination of Most Probable Number (MNP) of fecal coliform bacteria as well as determination of the water's $\mathrm{pH}$. Water temperature was measured before collection. Samples from 15 drinking places (13.3\%) were positive for Salmonella. The drinking places belonged to 12 of the sixty farms studied $(20 \%)$. The following serotypes were identified: $S$. dublin, S. newport, S. madelia, $S$. IV 43:g,z57:-, $S$. saphra, S. glostrup, S. IV ochsenzool; S. I9,12:i:and two new serotypes $S$. IV 41:z52:- and $S$. IV 50:d:-. Of the 113 samples studied $14(12,4 \%)$ presented MPN $/ 100 \mathrm{ml}$ of fecal coliforms above 4,000. There was no relationship between MPN $/ 100 \mathrm{ml}$ of fecal coliforms above 4,000 and positivity for Salmonella. Highest positivity both for Salmonella and MPN/100mL of fecal coliforms over 4,000 occurred at temperatures above $18^{\circ} \mathrm{C}$. As regards $\mathrm{pH}$, in both situations the highest positivity occurred between 6.0 and 7.0.

Keywords: Bacteriological water contamination, analysis. Salmonella, isolation. Enterobacteriaceae, analysis.

\section{Referências Bibliográficas}

\section{AMERICAN PUBLIC HEALTH ASSOCIATION.} Standard methods for the examination of water and waste-water. 15th ed. Washington, D.C., 1980.

2. BRITISH ASSOCLATION FOR THE ADVANCEMENT OF SCIENCE. Salmonella; the food poisoner. London, 1977.

3. CHRISTOVÃO, D. de A. et al. Condições sanitárias das águas de irrigação de hortas do Município de São Paulo. I. Determinação da intensidade de poluição fecal através do NMP de coliformes e de E. coli. Rev.Saúde pübl., S.Paulo, 1:3-11, 1967.

4. COMPANHIA DE TECNOLOGIA DE SANEAMENTO AMBIENTAL. Determinação do número mais provável de coliformes totais e fecais pela técnica de tubos múltiplos. São Paulo, 1978.

5. COMPANHIA DE TECNOLOGIA DE SANEAMENTO AMBIENTAL. Método semi-quantitativo para isolamento e identificação de Salmonella em água e esgoto. São Paulo, 1978.

6. CORREA, W.M. \& CORREA, C.N.M. Enfermidades inffecciosas dos mamiferos domésticos. Sảo Paulo, J.M. Varela, 1979.

7. COSTA, A. et al. Estudo da poluição em córregos de Ribeirão Preto, S.Paulo, através da determinação do NMP de coliformes e de Escherichia coli. In: Jornada Farmacêutica, 4a., Ribeirảo Preto, 1972. Resumos. Ribeirão Preto, 1972. p.29-30.

8. DECRETO $n^{2} 8.468$ de 8 de setembro de 1976: classificação das águas interiores situadas no território do Estado de São Paulo. Diário Oficial, S.Paulo, 9 set. 1976. p.4-18.

9. DYKSTRA, R.R Higiene animal y prevención de enfermedades. Barcelona, Editorial Labor, 1970. 
10. EDWARDS, P.R \& EWING, W.H. Identification of enterabacteriaceae. 3.ed. Minneapolis, Burgess Publishing, 1972. p.146-258.

11. FLEISS, J.L. Statistical methods for rates and proportions. New York, John Wiley \& Sons, 1973.

12. GELDREICH, E.E. Applying bacterological parameters to recreational water quality. J.Amer.Wat.Wks Assoc., 62:113-20, 1970.

13. GELDREICH, E.E. Buffalo lake recreational water quality: a study in bacteriological data interpretation. Wat. Res., 6:913-24,1972.

14. LE MINOR, L. \& BOCKEMUHL, J. Au schéma de Kauffmann - White. Ann. Inst. Pasteur Microbiol., $n^{2} 136$ B, p.57-61, 1985. Supplementum 28.

15. LEITÃO, M.F. de F. Salmonellas em águas fluviais e em alimentos nāo processados e industrializados de origem animal e vegetal no Estado de São Paulo. Sāo Paulo, 1979. [Tese - Doutoramento - Instituto de Ciências Biomédicas da Universidade de São Paulo].
16. MARTINS, M.T. et al. Isolamento de Salmonella em ambiente aquático: significado sanitário. Rev. Microbiol. 19:29-39, 1988.

17. SATAKE, T. et al. Estudo das condições sanitárias de águas de irrigaçāo de hortaliças do Município de Ribeirão Preto, São Paulo, por meio da determinação do Número Mais Provável do grupo coliforme, e de E. coli. Rev. Fac. Farm. Odont. Ribeiräo Preto, 13:11-22, 1976.

18. WILLIAMS, B.M. Environmental considerations in salmoneliosis. Vet. Rec., 96:318-21, 1975.

19. WRAY, C. Survival and spread of pathogenic bacteria of veterinary importance within the environment. Vet.Bull., 45:543-50, 1975.

Recebido para publicação em 19.7.1991

Reapresentado em 21.7.1992

Aprovado para publicação em 3.8.1992 